\title{
Development and Psychometric Evaluation of the Sport Psychology Attitudes- Revised Form: A Multiple Group Investigation
}

\author{
Scott B. Martin \\ University of North Texas \\ Michael Kellmann \\ Ruhr-University of Bochum, Germany \\ David Lavallee \\ University of Strathclyde, Scotland \\ Stephen J. Page \\ University of Cincinnati
}

\begin{abstract}
Exploratory and confirmatory factor analyses were conducted to develop a revised form of the Attitudes Toward Seeking Sport Psychology Consultation Questionnaire (ATSSPCQ; Martin, Wrisberg, Beitel, \& Lounsbury, 1997). The 50 -item ATSSPCQ was administered to 533 athletes $(M=18.03 \pm 2.71)$. Exploratory alpha factor analysis with varimax rotation produced four factors: (a) stigma tolerance, (b) confidence in sport psychology consultation, (c) personal openness, and (d) cultural preference. The new questionnaire, the Sport Psychology Attitudes - Revised form (SPA-R), was then administered to 379 United States, 234 United Kingdom, and 443 German athletes $(M=20.37 \pm$ 5.13). Confirmatory factor analysis demonstrated the factorial validity of the four-factor model for the SPA-R for male and female athletes, late adolescent
\end{abstract}

Scott B. Martin is with the Department of Kinesiology, Health Promotion, and Recreation at the University of North Texas, Denton, TX 76203-6857. E-mail: <Smartin@coefs.coe.unt.edu>. Michael Kellmann is with the Faculty of Sport Science at the Ruhr-University of Bochum, Germany; David Lavallee is with the Scottish School of Sport Studies, University of Strathclyde, Glasgow, Scotland; Stephen J. Page is with the Department of Physical Medicine and Rehabilitation at the University of Cincinnati College of Medicine, Cincinnati, OH 45267. 
and adult athletes, and athletes from different countries. Psychometric characteristics of the SPA-R are described and implications related to sport psychology consultation and research are discussed.

Public interest in sport psychology has increased over the past decade, which is partially reflected in mainstream media and film. For instance, the movie starring Kevin Costner, Tin Cup, provided the viewing audience a laugh or two in the form of the unethical behavior of a counselor working with a down and out golfer (Foster, Shelton, \& Lester, 1996). Likewise, the TV hit show, Frasier, dedicated an episode to strategies the main character's brother used to get courtside seats and recognition for the consulting he was doing with an athlete (Lloyd \& Lee, 1997). Not all of the media coverage pokes fun at individuals receiving or being provided psychological skills assistance. Recently, the cover story of the U.S. News and World Report was dedicated to success and sport psychology (Tolson, 2000). Likewise, Goin' Deep, a weekly news magazine hosted by Chris Myers on FOX Sports Network, explores all aspects of the world of sports (Jackson, 1998). Probing deeply behind the scenes, Goin' Deep has dedicated several shows to the concept of mental training and to the work sport psychology practitioners are doing with professional athletes and teams (Jackson, 1998).

Despite the increased attention given to sport psychology and growth in the number of psychologists working with athletes and coaches, many athletes and coaches remain hesitant to use sport psychology services (Martin, 1998; Ravizza, 1988). Sport psychology journals are teeming with examples of studies assessing the efficacy of performance enhancement interventions. Nevertheless, relatively few researchers have investigated peoples' attitudes and beliefs about sport psychology (e.g., Brooks \& Bull, 1999; Linder, Brewer, Van Raalte, \& DeLange, 1991; Linder, Pillow, \& Reno, 1989; Martin, Wrisberg, Beitel, \& Lounsbury, 1997; Van Raalte, Brewer, Brewer, \& Linder, 1992; Van Raalte, Brewer, Linder, \& DeLange, 1990). Research investigating the usefulness of interventions has often neglected to determine (a) athletes' and coaches' attitudes about sport psychology, (b) whether athletes and coaches were interested in learning sport psychological skills, and (c) whether athletes or coaches were receptive to working with a sport psychology consultant (SPC). As is the case in any service-related vocation, knowledge of consumers' preferences and perceptions is important for SPCs who wish to better serve their clients.

Recently, researchers have attempted to develop a valid and reliable instrument to accurately assess athletes' attitudes about sport psychology consulting. Martin and colleagues (1997) developed the Attitudes Toward Seeking Sport Psychology Consultation Questionnaire (ATSSPCQ) to assess NCAA Division I athletes' perceptions of SPCs. The ATSSPCQ was based in part on the Attitudes Toward Seeking Professional Psychological Help (ATSPPH; Fischer \& Farina, 1995; Fischer \& Turner, 1970) and previous research on perceptions of sport and counseling psychology (see Martin et al., 2001). For example, some athletes approach a SPC with a degree of apprehension for fear of being stigmatized by others (e.g., coaches, teammates) as having psychological problems (Linder et al., 1989; Van Raalte, et al., 1992; Wrisberg \& Martin, 1994). Likewise, some individuals have been found to prefer instructors, counselors, and coaches who are ethnically and racially similar to their own perceived identity (Anshel, 1990; Atkinson \& Lowe, 1995; Wrisberg \& Martin, 1994). In addition, athletes possessing high intentions 
to practice mental training skills are likely to believe that sport psychology has positive effects on their performance (Greaser, 1992). Similarly, confidence in sport psychology is an important personal characteristic influencing adherence to a mental skills training program (Bull, 1995). Thus, the original intent of the ATSSPCQ was to measure college athletes' stigmatization, recognition of need, confidence in sport psychology, interpersonal openness, and social desirability. Nonetheless, the resultant principal components analysis (PCA) conducted by Martin et al. (1997) indicated that the 50 items loaded only on three factors: (a) stigma tolerance, (b) recognition of need/confidence in SPC, and (c) personal openness.

In addition to using PCA to determine the factor structure of the ATSSPCQ, Martin and colleagues (1997) used two reliability-estimation procedures to obtain a better understanding of the instrument's measurement capabilities. Cronbach coefficient alpha obtained for stigma tolerance, recognition of need/confidence, and personal openness were $.89, .81$, and .64 , respectively. Test-retest correlations for stigma tolerance, recognition of need/confidence, and personal openness were $.93, .88$, and .85 , respectively. Martin and colleagues (1997) also examined the validity of the instrument by performing paired t-tests on the items of the ATSSPCQ and the Attitudes Toward Seeking Professional Psychological Help (ATSPPH) questionnaire (Fischer \& Turner, 1970). None of the comparisons produced a significant difference.

The Martin et al. (1997) study was only a first step and was limited in a number of ways (e.g., a small sample). The researchers acknowledged some of the limitations and suggested several steps that should be taken to validate the instrument, such as conducting confirmatory factor analysis (CFA) on a new sample. CFA, an application of structural equation modeling (SEM) that deals directly with how well measures reflect their intended constructs, is both more rigorous and more parsimonious than the more traditional exploratory factor analysis (EFA) techniques (Kelloway, 1998). Although Martin and colleagues' study had several limitations, the findings did support Ravizza's (1988) notion that some athletes might be hesitant to seek out the services provided by SPCs.

Independent of one another, Harmison and Petrie (1998) and Martin (1998) tried to replicate and extend the efforts of Martin and colleagues (1997) to objectively assess athletes' attitudes toward seeking sport psychology consultation using EFA procedures. Harmison and Petrie administered the ATSSPCQ to 405 athletes representing NCAA Division I, II, and III schools. A principal factor analysis with oblique rotation criteria produced a three-factor solution that accounted for $29 \%$ of the overall variance, which can be troublesome (see Tinsley \& Tinsley, 1987). The three factors were (a) confidence in sport psychology (19 items), (b) stigma tolerance ( 8 items), and (c) preference for racial similarity (4 items). The remaining nineteen items of the 50-item ATSSPCQ failed to load higher than the cut-off value of .40 on any of the factors. Estimates of validity revealed the ATSSPCQ to have good concurrent and adequate construct validity (Harmison \& Petrie, 1998).

Similarly, Martin (1998) administered the ATSSPCQ to 505 high school athletes ranging from 14 to 18 years of age. Alpha factor analyses with varimax rotation criteria suggested a 3 -factor solution accounting for $35 \%$ of the total variance and a 4 -factor solution representing $40 \%$ of the overall response variance. Subsequent item selection procedures resulted in fourteen items being deleted based on low inter-item correlations, and seven items were removed due to a loading of less 
than .40 and a loading on other factors. Finally, split and total sample reliabilities and factor loadings indicated that the four-factor solution was most replicable across samples. The 4-factors representing the revised inventory were (a) stigma tolerance (8 items), (b) confidence in SPC (9 items), (c) personal openness (8 items), and (d) cultural preference (4 items). The 3 and 4 factor solutions were similar to that of the factor analysis performed earlier (Martin et al., 1997). Explicitly, the stigma tolerance and cultural preference scales made up the stigma tolerance scale in both 3-factor solutions.

Unfortunately, neither Harmison and Petrie (1998) nor Martin (1998) had samples large enough to perform both EFA and CFA. Theoretical and empirical support exists for additional instrument evaluation. A logical next step would be to refine the original ATSSPCQ based on the more recent findings using appropriate sample size. Possessing a valid and reliable instrument that measures athletes' perceptions and attitudes toward sport psychology consultation could help SPCs promote positive attitudes about seeking psychological help and foster a less stereotypical and myth-laden view of sport psychology consulting. Therefore, the primary purpose of the present study was to extend existing research on sport psychology attitudes by (a) refining the ATSSPCQ developed by Martin and colleagues (1997) using an EFA approach to determine initial factors and (b) examining the validity and reliability of the revised instrument using CFA procedures.

\section{Exploratory Factor Analysis}

\section{Participants}

The original 50-item ATSSPCQ (see Martin et al., 1997) was administered to a total of 647 high school and college athletes. Of the total number of questionnaires distributed, 533 complete, useable forms were returned, providing an $82 \%$ response rate. The sample included 244 male and 289 female athletes ranging from 14 to 26 years of age $(M=18.03 \pm 2.71)$. Represented in the sample were athletes from the sports of baseball $(n=30)$, basketball $(n=79)$, American football $(n=73)$, golf $(n=21)$, gymnastics $(n=4)$, soccer $(n=53)$, softball $(n=36)$, swimming $(n=25)$, tennis $(n=22)$, track and field $(n=79)$, volleyball $(n=32)$, and 79 who participated on more than one sport team. The athletes had an average of $4.76 \pm 1.7$ years of sport experience. Of the 533 athletes, 333 were Caucasian, 75 were AfricanAmerican, 96 were Latino, 20 were Asian American, and 9 designated other.

\section{Procedures}

After obtaining institutional review board approval, coaches were contacted and subsequently agreed to participate in the study and to recruit athletes involved in their programs. The ATSSPCQ was administered to athletes during team sport meetings and classes. Members of the research team read instructions for completing the inventory and obtained informed consent from the athletes and their parents prior to questionnaire completion. Then, each participant was given an answer and question sheet, with the instructions directing respondents to individually report their attitudes and beliefs about sport psychology on a 7-point Likert scale ranging from 1 (strongly disagree) to 7 (strongly agree). Test administrators answered any questions and instructed participants to answer items as honestly as possible. Respondents required approximately 15 minutes to complete the questionnaire. 
The strategy was to begin with an intuitively derived number of items by identifying, through EFA, item clusters corresponding to specific attitudes toward seeking sport psychology consultation. To investigate the relationship among athletes' attitudes toward sport psychology consultation, an alpha factor analysis was performed on the ATSSPCQ items. The following criteria (see Nunnally \& Berstein, 1994; Tinsley \& Tinsley, 1987) were considered in determining the number of factors to rotate: (a) the number of factors with eigenvalues of at least 1.0, (b) the scree test, (c) the percentage of variance accounted for by each factor, (d) the percentage of total variance accounted for by the retained factors, (e) the number of interpretable factors, and (f) factor analyzing "odd-even" split halves subsamples independently. Item variance, item mean, the internal consistency of each scale, and the degree of overlap among the scales was also considered. An attempt was made to maintain scale values between .60 and .85 and to minimize the overlap among scales.

\section{Examination of Factor Structure and Reliability Estimates}

An alpha factor analysis with varimax rotation suggested a 3-factor solution accounting for $40 \%$ of the total variance and a 4 -factor solution representing $46 \%$ of the overall response variance. The split-sample and total sample reliabilities and factor loadings indicated that the 4-factor solution was most replicable across segregated samples. The factors representing the revised inventory were (a) stigma tolerance, (b) confidence in SPC, (c) personal openness, and (d) cultural preference. The factor solutions in the present study were similar to that of the factor analysis performed earlier (Martin et al., 1997; Martin, 1998). That is, the stigma tolerance and cultural preference scales made up the stigma tolerance scale in the 3 factor solutions.

As a result of the item selection process, a total of 25 items were deleted from the initial pool of 50 items. Fourteen items (i.e., items 1, 4, 7, 8, 10, 20, 30, $32,33,35,39,40,45,48)$ were deleted based on low inter-item correlations, and eleven items (i.e., items 3, 6, 9, 14, 16, 17, 21, 23, 31, 42, 46) were removed due to a loading of less than .50 or a loading on other factors. Of the 25 items retained, 6 were assigned to scales different from the ATSSPCQ scale. Four of these items represented a new factor, cultural preference, which originally loaded on the ATSSPCQ stigma tolerance scale (see Martin et al., 1997). The factor solution (see Table 1) obtained in the present study is more clearly related to the theoretically derived constructs on which the ATSSPCQ was developed. Hereafter, the revised ATSSPCQ short instrument is referred to as the Sport Psychology Attitudes - Revised (SPA-R) form.

Cronbach's coefficient alpha was calculated for the entire SPA-R form and for each of the derived factors in order to determine levels of internal consistency of the derived factors. Coefficient alphas of .84, .82, .61, and .66 were obtained for factors 1 (stigma tolerance), 2 (confidence in SPC), 3 (personal openness), and 4 (cultural preference), respectively. Applying more than one reliability-estimation procedure enriches the understanding of the instrument's measurement qualities. Thus, the instrument was administered twice over an 8-week period to a sample of 19 Caucasian high school student-athletes ranging from 15 to 18 years of age. None of these athletes were members of the original sample. Intraclass coefficients (ICC) were calculated to determine the extent of difference between respondents' scores on the two administrations of the test. The test-retest ICCs for the SPA-R 


\begin{tabular}{lllll}
\hline & \multicolumn{4}{c}{ Factor } \\
\cline { 2 - 4 } Original Item \#, (New Item \#) and Item & 1 & 2 & 3 & 4 \\
\hline
\end{tabular}

Stigma Tolerance

37 (18) Not want someone to know about me receiving help from a SPC.

$\begin{array}{llll}.77 & .04 & .19 & .02\end{array}$

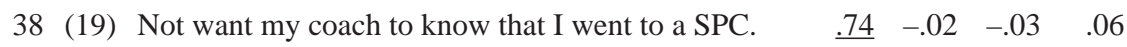

$\begin{array}{lllllll}43 & \text { (21) Not want other athletes to know that I went to a SPC. } & \underline{.73} & . & .00 & .11 & .11\end{array}$

47 (23) Coach would think less of me if I went to a SPC. $\quad \begin{array}{llllll}.70 & -.08 & .08 & .07\end{array}$

27 (13) Seeing a SPC is bad for an athlete's reputation. $\quad \begin{array}{lllllll}.64 & -.20 & .64 & .16\end{array}$

22 (9) Feel uneasy going to a SPC because people would disapprove.

12 (4) Would not go to a SPC because another athlete would harass me.

$\begin{array}{lll}.55 & -.13 & -.15\end{array}$

Confidence in SPC

36 (17) A SPC would help me perform better under pressure. $-.04 \quad \underline{.76} \quad-.03 \quad .00$

29 (15) Would get help from a SPC if upset about my sport performance.

$\begin{array}{llll}-.04 \quad \underline{.75} & -.11 \quad .02\end{array}$

19 (8) Would like the help of a SPC to better understand myself.

$\begin{array}{llll}-.02 & .73 & -.07 & -.05\end{array}$

41 (20) SPC could help me fine tune my sport performance. $\quad-.19 \quad \underline{.71} \quad-.07 \quad-.04$

2 (1) A SPC can help improve mental toughness. $\quad-\quad-.26 \quad \underline{.60} \quad .06 \quad-.08$

44 (22) Have felt lost and would have welcomed professional advice.

$\begin{array}{llll}.00 & .60 & -.14 & .12\end{array}$

26 (12) Would feel most secure in receiving help from a SPC. $-.17 \quad \underline{.54} \quad .21 \quad-.02$

11 (3) If teammate asked my advice, I might recommend a SPC.

$\begin{array}{llll}.02 & .52 & -.17 & -.16\end{array}$

Personal Openness

18 (7) Good idea for avoiding worries is to keep one's mind on a job.

$\begin{array}{llll}.05 & .19 \quad .58 & .04\end{array}$

49 (24) Athletes with a strong character overcome conflicts by themselves.

$$
\begin{array}{llll}
.13 & -.15 \quad \underline{.58} \quad .16
\end{array}
$$

24 (10) Something respectable about willing to cope with conflicts.

$\begin{array}{llll}.05 & -.04 & \underline{.55} & .05 \\ .05 & -.28 & \underline{.55} & .13 \\ .02 & -.08 & .54 & .03\end{array}$

34 (16) Emotional difficulties tend to work themselves out in time. 


\section{Table 1 (continued)}

Original Item \#, (New Item \#) and Item

\begin{tabular}{llll}
\multicolumn{4}{l}{ Factor } \\
\hline 1 & 2 & 3 & 4
\end{tabular}

28 (14) There are experiences in my life that I would not discuss with anyone.

$\begin{array}{llll}.02 & -.02 & \underline{.52} & -.04\end{array}$

Cultural Preference

5 (2) Respect the opinions of my own culture more than other cultures.

$\begin{array}{rrrr}.21 & -.02 & .00 & \underline{.67} \\ .04 & -.09 & .09 & \underline{.75} \\ .32 & -.04 & .07 & \underline{.70} \\ .13 & .08 & .12 & \underline{.54}\end{array}$

15 (6) Athletes I associate with are of the same race as me.

Eigenvalues

$\begin{array}{llll}5.00 & 3.07 & 1.93 & 1.44\end{array}$

$\%$ of Variance

$\begin{array}{llll}14.96 & 14.33 & 8.31 & 8.20\end{array}$

Factor Reliability

$\begin{array}{llll}.84 & .82 & .61 & .66\end{array}$

form were .90 for stigma tolerance, .83 for confidence in SPC, .71 for personal openness, and .70 for cultural preference. All test-retest correlations for the 25 items were also moderately high, ranging in value from .62 to .95 , with the overall correlation being .81 .

Descriptive statistics for participants' responses to each item of the ATSSPCQ are presented in Table 2. Scores higher than a mean average of five on the stigma tolerance factor indicate a negative attitude by respondents toward seeking sport psychology consultation. Conversely, high scores on the confidence in SPC factor represent respondents' belief that sport psychology consultation and mental training is useful. High scores on the personal openness factor suggest an unwillingness to partake in a sport psychology consultation or mental training. Finally, high scores on the cultural preference factor indicated respondents' strong identity to their own nationality, ethnicity, culture, or race.

\section{Confirmatory Factor Analysis}

\section{Participants}

A total of 1,077 athletes (382 United States, 239 British, and 456 German) responded to the SPA-R survey. Of this total, 1,056 (379 United States, 234 British, and 443 German) complete useable forms were collected. Informed consent was obtained prior to the completion of the questionnaire. The sample included 478 
Table 2 Means, Standard Deviations, and Skewness for each Item on SPA-R

\begin{tabular}{rrrrrrrr}
\hline Item & $M$ & $S D$ & Skew & Item & $M$ & $S D$ & Skew \\
\hline 1 & 5.56 & 1.23 & -1.31 & 14 & 4.56 & 1.85 & -.37 \\
2 & 2.37 & 1.62 & 1.11 & 15 & 4.22 & 1.52 & -.26 \\
3 & 4.01 & 1.43 & -.13 & 16 & 4.06 & 1.48 & -.17 \\
4 & 2.31 & 1.33 & 1.12 & 17 & 4.63 & 1.41 & -.44 \\
5 & 4.74 & 1.83 & -.55 & 18 & 3.01 & 1.43 & .63 \\
6 & 4.10 & 2.01 & -.16 & 19 & 2.73 & 1.41 & .80 \\
7 & 4.87 & 1.54 & -.62 & 20 & 4.76 & 1.40 & -.60 \\
8 & 4.19 & 1.55 & -.26 & 21 & 2.94 & 1.36 & .61 \\
9 & 2.53 & 1.33 & .95 & 22 & 4.39 & 1.66 & -.39 \\
10 & 3.96 & 1.51 & .01 & 23 & 2.55 & 1.31 & .80 \\
11 & 3.58 & 1.77 & .13 & 24 & 3.98 & 1.53 & -.01 \\
12 & 4.50 & 1.28 & -.29 & 25 & 2.80 & 1.63 & .64 \\
13 & 2.27 & 1.23 & 1.13 & & & & \\
14 & 4.56 & 1.85 & -.37 & & & & \\
15 & 4.22 & 1.52 & -.26 & & & & \\
\hline
\end{tabular}

male and 578 female athletes ranging from 14 to 32 years of age (20.37 \pm 5.13$)$. Represented in the sample were athletes from the sports of baseball $(n=25)$, basketball $(n=83)$, boxing/karate $(n=17)$, cricket $(n=9)$, American football $(n=54)$, golf $(n=25)$, gymnastics $(n=28)$, handball $(n=32)$, netball $(n=18)$, rowing/ canoeing $(n=133)$, soccer $(n=164)$, softball $(n=22)$, swimming $(n=73)$, tennis $(n=48)$, track and field $(n=106)$, triathlon $(n=13)$, volleyball $(n=63)$, wrestling $(n=7)$, and 136 who participated on more than one sport team or marked the "other sport" option. The athletes had an average of $4.32+1.5$ years of sport experience.

\section{Procedures}

The new questionnaire, SPA-R instrument, was administered to United States, United Kingdom, and German athletes who participated in high school, club, or college sports during team and class meetings to determine the relative strength of the four-factor model for adequately describing attitudes toward seeking sport psychology consultation. Prior to administration to the German sample, the SPA-R was translated to German and then independent of the first translation, it was translated back into English to maximize content equivalence and to lessen interpretation difficulties (i.e., the back-translation method). Slight wording changes were made to the demographic section of the German and United Kingdom SPA-R form (e.g., sport type and education). The questionnaire administration procedures mentioned previously for the EFA study were followed for the CFA study.

Once the data was collected, a confirmatory factor analysis approach (see Jöreskog, \& Sörbom, 1993) was then conducted with LISREL 8.3 (du Toit, du Toit, 
Jöreskog, \& Sörbom, 1999) unweighted least squares (ULS) and maximum likelihood (ML) estimation procedures, using a covariance matrix as data input to evaluate data fit to a four-factor model, a three-factor model, and a two factor model. PRELIS (Jöreskog \& Sörbom, 1993) was used to generate the polychoric correlation and its corresponding asymptotic covariance matrix. The ULS method was used because the measurement units were the same and the summative scales have previously been shown to have roughly interval properties (Schumacker \& Lomax, 1996). The ML estimator was also used since it is typically reported and is relatively robust with regard to nonnormal distribution (Hu \& Bentler, 1999). The advantages of ULS for factor models with dichotomous data includes a superiority over the use of phi coefficients and relative economy, whereas ML provides better estimates of standard errors of estimation and statistical tests of model fit (see Mislevy, 1986). Thus, the various estimation methods provide different results in the presence of variable measurement scale, variance-covariance, and normality assumptions (Schumacker \& Beyerlein, 2000).

Although SEM fit indexes have no single statistical test of significance that identifies a correct model given the sample data, Schumacker and Lomax (1996) recommend that various goodness-of-fit (GOF) criteria be used in combination to assess model fit, model comparison, and model parsimony. Absolute and incremental model fit indexes commonly used are chi-square/degrees of freedom ratio or $Q$ ratio $\left(\chi^{2} / \mathrm{df}\right)$, the Root Mean Square Error of Approximation (RMSEA), the Standardized Root-Mean-Square Residual (SRMR), the Goodness of Fit Index (GFI), the Adjusted Goodness of Fit Index (AGFI), the Nonnormed Fit Index (NNFI), the Comparative Fit Index (CFI), and the Expected Cross-Validation Index (ECVI). These criteria are based on differences between the observed and model-implied correlation or covariance matrix (Hu \& Bentler, 1999; Schumacker \& Lomax, 1996).

When parallel data exist across groups, a question that often emerges is whether the factor structure of a given measure is applicable across samples of participants who differ in ethnicity, gender, age, or any other personal characteristic that might affect responses to the measure (Floyd \& Widaman, 1995). Multiple group measurement invariance testing is a powerful way to determine the equivalence of factor solutions across samples (Marsh, 1994). Thus, the SPA-R instrument and obtained factor structure were generalized through a series of multiple group measurement invariance tests with LISREL 8.3 (du Toit et al., 1999) using both ULS and ML estimation procedures. Although there is no consensus on the ordering of the subsequent models of invariance, the following hierarchy for measurement models has been outlined: (a) a baseline model with no invariance constraints specified across samples was estimated; (b) a model specifying factor loadings, factor correlations, and error variances invariant; (c) a model specifying factor loadings invariant; and (d) a model specifying factor loadings and factor correlations invariant (see Jöreskog \& Sörbom, 1993; Marsh, 1994). The baseline (noninvariant or freely estimated) model served as a comparison standard for the remaining models. Relative Noncentrality Index (RNI), Tucker-Lewis Index (TLI), and chi-square difference test were calculated in addition to RMSEA, GFI, CFI, and NNFI. RNI and TLI can be useful in evaluating relative lack of fit attributable to invariance constraints (see Hu \& Bentler, 1999; Marsh, 1994). The chi-square difference test was used to evaluate the baseline model with the designated model. 


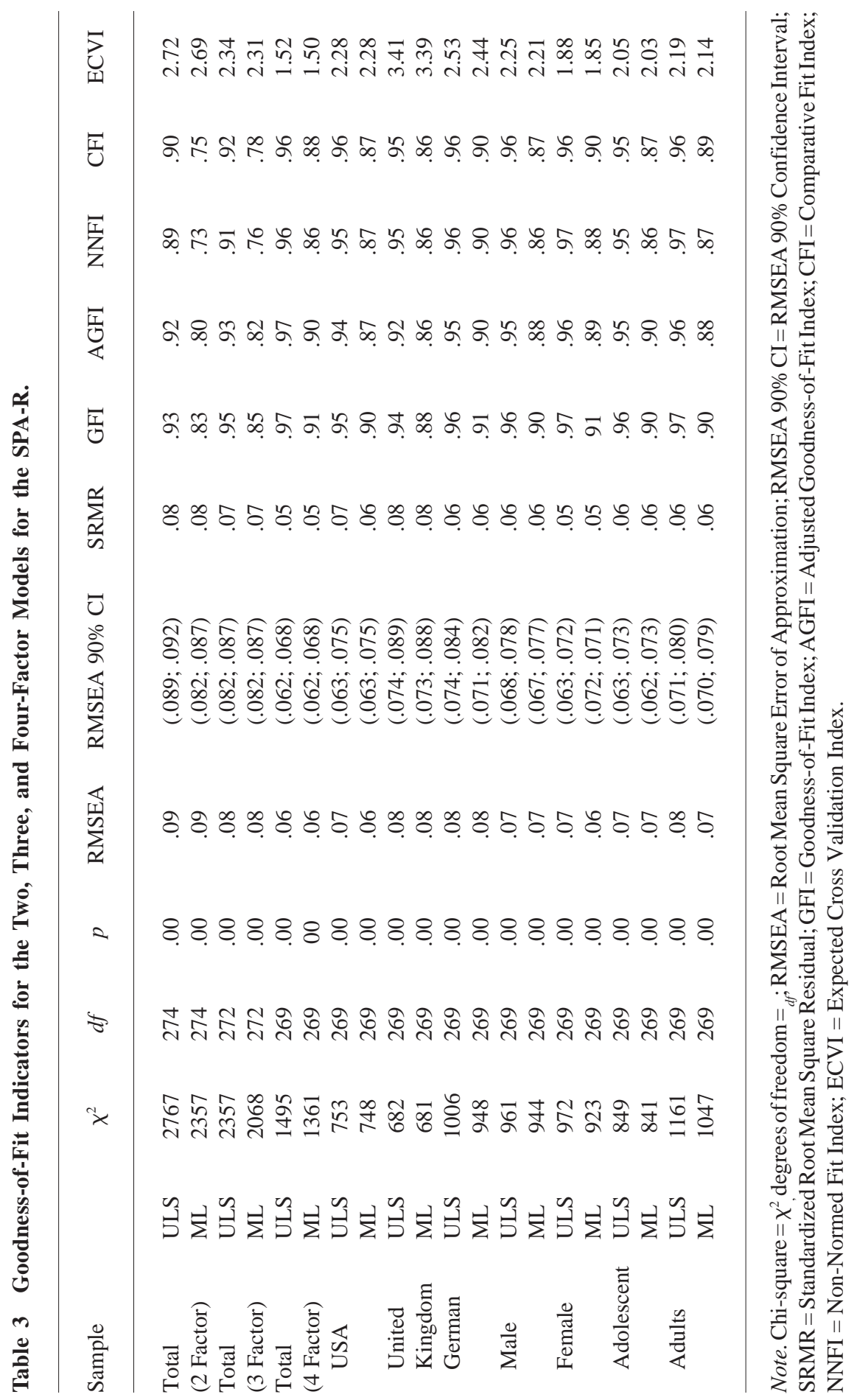




\section{Assessment of Fit}

In the present study, Jöreskog and Sörbom (1993) criterion of sample size was met (i.e., $25(25-1) / 2=300, \mathrm{k}=25)$. However, an even larger sample size would have been desirable to achieve more reliable estimations and may have provided an opportunity to conduct additional CFA procedures to investigate first-order factors (i.e., the 25 items). As expected, the ULS and ML estimation procedures provided different values for the indexes (see Table 3 ). ULS fit values were usually more favorable than the ML fit values. Initial comparisons between the four-factor model identified in the EFA study, a three-factor model, and a two-factor conceptual model were made using the statistics mentioned in the previous section. Across the goodness-of-fit indexes, the four-factor model (see Figure 1) was the best fit compared with the competing models. The four-factor model had the lowest chi-square/degrees of freedom ratio ( $\left.\chi^{2} / \mathrm{df}\right)$, RMSEA, SRMR, and ECVI and the highest GFI, AGFI, NNFI, and CFI.

The analysis using the four-factor model revealed a RMSEA of 0.08 or less for the total sample and the segregated samples. RMSEA values below 0.10 indicate a good fit to the data, values below 0.05 a very good fit to the data, and values below 0.01 indicate an outstanding fit to the data (Browne \& Cudeck, 1993; Steiger, 1990). The total sample and the segregated samples analyses also revealed SRMRs of 0.08 or less. The GFIs, AGFIs, NNFIs, and CFIs were all 0.86 or higher. The GFI is based on a ratio of the sum of the squared discrepancies to the observed variance, and the AGFI adjusts the GFI for degrees of freedom in the model. The GFI, AGFI, NNFI, and CFI can range from 0 (no fit) to 1 (perfect fit) and typically, values exceeding 0.85 indicate adequate fit and values exceeding 0.90 a good fit to the data (Kelloway, 1998; Schumacker \& Lomax, 1996). The GOF criteria were all within the acceptable range of model fit. Thus, the results of the CFA indicated that the factor structure produced by the EFA was reliable.

As with the individual sample analyses, ULS and ML estimation procedures generally provided different values (see Table 4). Using the approach outlined above (Jöreskog and Sörbom, 1993; Marsh, 1994), the difference in chi-square statistic between the various baseline models and some of the designated or alternative models were significant. There seems to be insufficient evidence that the factor correlations differ across the respective groups. Although there is some evidence that the factor loadings and the error variances differ across the particular groups, the fit did not decrease in terms of the alternative fit indexes. Specifically, the chi square difference tests under the ML estimation procedure indicated adequate evidence of invariant factor loadings for the respective groups, whereas under the ULS method, the chi square difference tests for the factor loadings invariant model was significant for gender and age. Some SEM researchers suggest that reasonable fit indexes may indicate that the designated models are not appreciably different (Marsh, 1994; Steenkamp \& Baumgartner, 1998). In all cases, the alternative models did not change dramatically from their respective baseline model.

\section{Discussion}

The findings of this investigation extend the work of Martin and colleagues (1997, 1998) and others (e.g., Harmison \& Petrie, 1998; Linder et al., 1991; Van Raalte et al., 1992). The results of the present study support a shorter instrument with a 


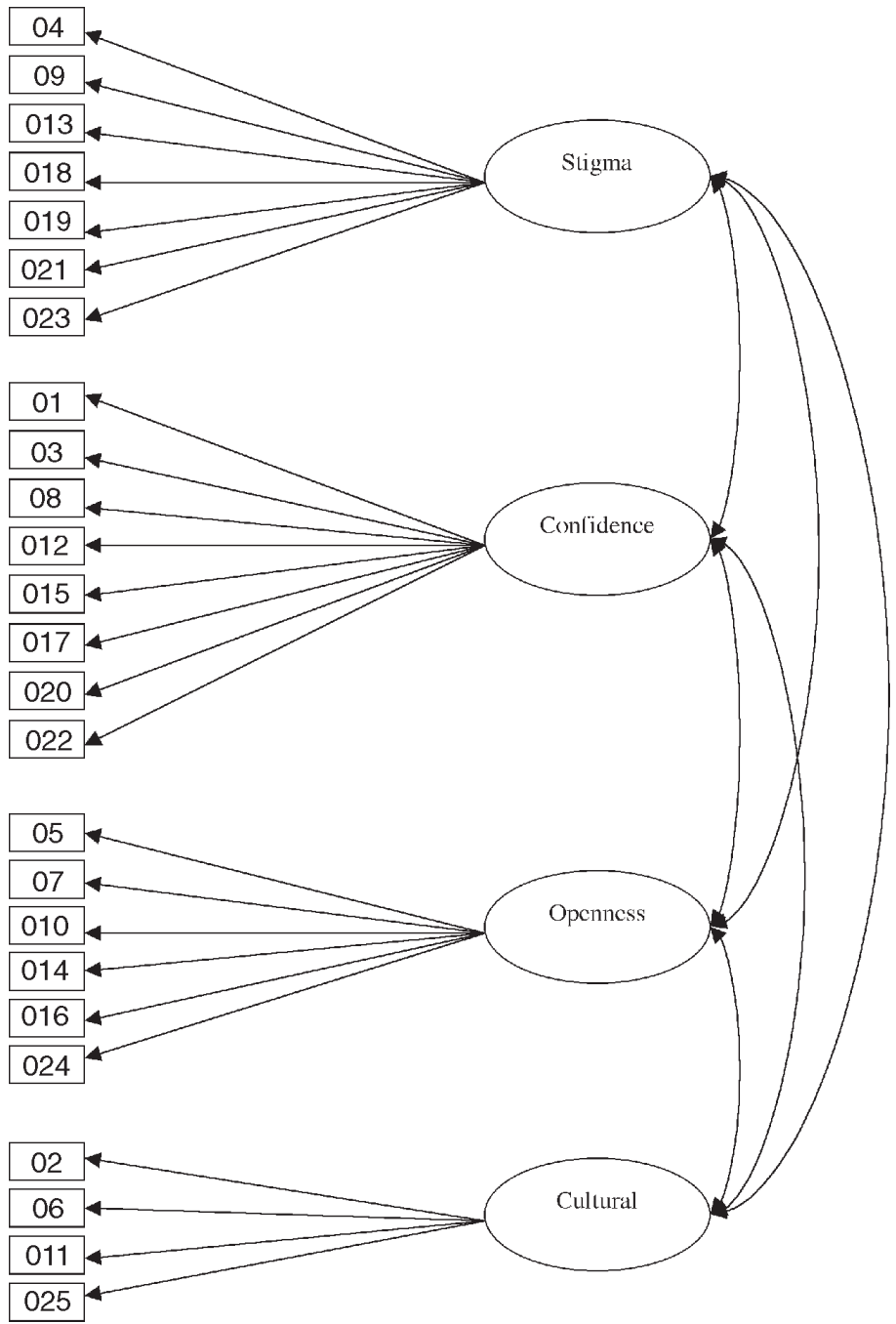

Figure 1 - Four-factor model. Rectangles are measured variables, and ovals are the latent constructs.

4-factor solution. The factor solution is robust and more clearly related to the theoretically derived constructs on which the ATSSPCQ was developed (Martin et al., 1997). The procedures in this study provide added generalizability and stability to the resultant factors. Multiple criteria were used in determining the factors to be extracted and rotated in the EFA procedures on the initial sample. As a result, the number of components identified is somewhat method independent. The EFA factor solution adopted was selected on the basis of the stability of the solution across independently factored samples, a split-half, and total procedure. The cultural pref- 


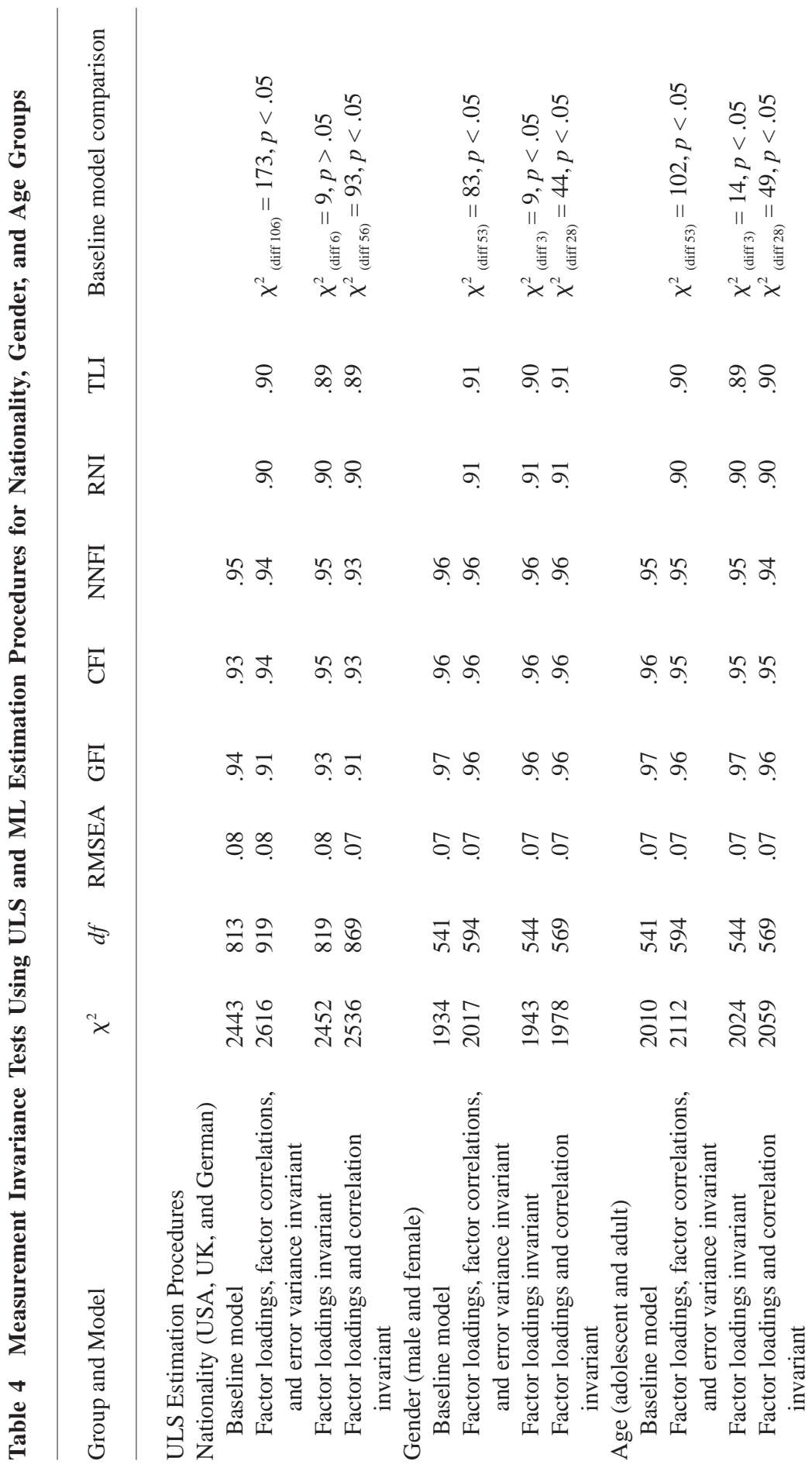




$$
\text { ํ. }
$$

i.

$\because \quad i v$

ते 0 in

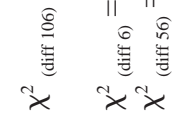

$\bar{\infty} \infty \infty$

$\bar{\infty} \infty \stackrel{\infty}{\infty} \stackrel{\infty}{\infty}$

$\infty \infty . \infty$

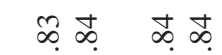

$\bar{\infty}, \infty \quad \infty$

$\infty \varnothing \infty$

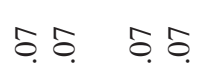

क के के

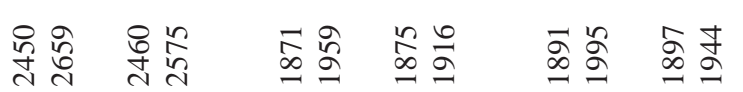

ఫ. ఫ্.

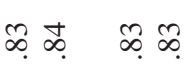

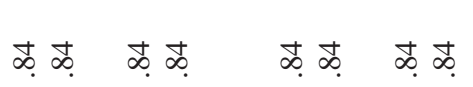

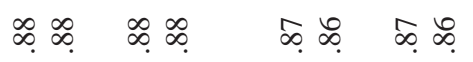

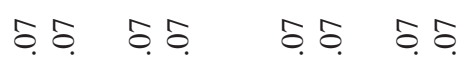

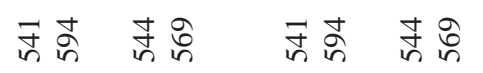

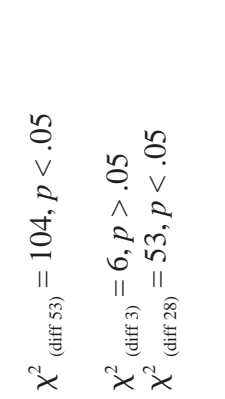

(1)
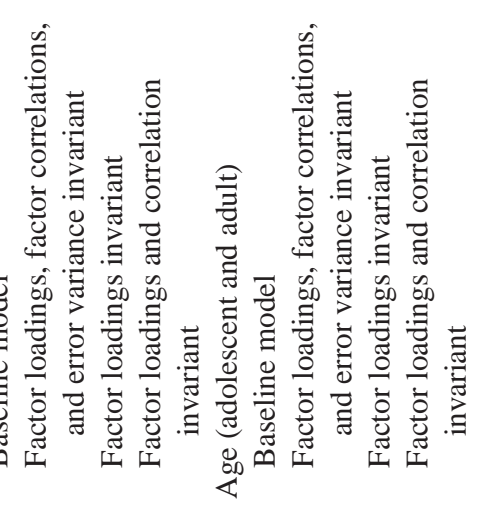

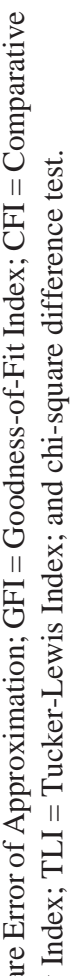

荧

窟

욜

$\prod_{4} \frac{\pi}{2}$

$\sum_{2}^{\infty} \frac{11}{7}$

5

Iㅏㅄ

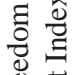

进

4 造

巡

究

×

II II

离䆓

它

:

之语 
erence factor originally loaded on the ATSSPCQ stigma tolerance scale (see Martin et al., 1997). Harmison and Petrie (1998) and Martin (1998) identified this factor independent of one another. The finding that stigma tolerance and cultural preference are distinct yet similar factors is not contradictory; both factors represent stereotypes or an identity with which a person is most familiar. The additional subscale, cultural preference, may help SPCs respond more effectively to clients' cultural identity and preference (see Andersen, 1993; Anshel, 1990; Brooks \& Bull, 1999; Lee \& Rotella, 1991; Messner, 1992; Yambor \& Connelly, 1991).

Two of the subscales (i.e., personal openness and cultural preference) have coefficient alphas in the $.60 \mathrm{~s}$ and may be viewed as tolerable considering the number of items that represent each subscale. Cronbach (1951) indicated that coefficient alphas are greatly influenced by the number of items in the measure and the extent of the covariation among items. When reducing the number of items per subscale or when a limited number of items exist, low alpha coefficients can provide a practical underestimate of subscale item intercorrelations, which are the basis for internal consistency (Nunnally \& Berstein, 1994). Increasing the number of items in the subscales would not necessarily be useful, especially if the factorial integrity of the measure is not preserved. The addition of a single item of the same average intercorrelation for cultural preference would put the alpha value over the often-cited value of .70 (see Pedhazur \& Schmelkin, 1991). On the other hand, the .61 alpha for the 6-item subscale, personal openness, is low and would need three additional related items to advance the alpha above .70 . Based on this alone, some researchers may have misgivings about the internal consistency of factor 3, personal openness. There is a trade-off between brevity and reliability. The test-retest reliabilities of the subscales were above .70. Taken together, the two reliabilityestimate procedures (i.e., internal-consistency and stability) of the SPA-R could be viewed as sufficient. In addition, it is worth mentioning that each of the SPA-R subscales seem to have adequately robust factor structure and could be used independently if preferred.

CFA was then performed using alternative models and on multiple samples from different groups and countries. The four-factor model identified in the EFA proved better than a two-factor or three-factor model. The four-factor model was then tested using multiple groups. Specifically, the four-factor model was tested separately for male and female athletes because of reported differences in physical activity and seeking assistance experiences (e.g., Brooks \& Bull, 1999; Coakley \& White, 1992; Yambor, \& Connelly, 1991). In addition, the four-factor model was assessed for adolescent and adult athletes due to the possibility of differences in the relationship between maturity and seeking psychological help (e.g., Esters, Cooker, \& Ittenbach, 1998; Garland, \& Zigler, 1994; Goldberg, \& Chandler, 1995; Malina, 1996). Furthermore, the model put forth was evaluated for athletes from different countries on the account of the possibility of differences in physical activity and seeking psychological help experiences of people from various regions of the world (e.g., Kenney, 1994; Van Raalte, Brewer, Matheson, \& Brewer, 1996). The findings of the total sample, multiple independent sample, and the measurement invariance tests indicate that the four-factor model has adequate stability, recognizable and theoretically consistent across groups and countries regardless of culture differences. This suggests that the items of the SPA-R form measured relatively the same factors in each group. Therefore, because of these procedures and the demonstrated reliability of the scales, improved replicability is anticipated 
for future samples.

Using the SPA-R instrument may allow sport psychology practitioners to determine whether individuals are (a) interested in learning mental skills, (b) receptive to sport psychology consultation, (c) confident in the consultant's abilities, or (d) tolerant of the consultant's personal characteristics. Practitioners should evaluate each subscale separately to accurately interpret their clients' attitudes toward sport psychology consultation. For example, a moderately high score on the confidence factor would likely be a positive prognostic sign, whereas extremely high scores on the confidence factor could be characteristic of clients who naively expect the SPC to "fix" their problem without their having to make an effort.

\section{Conclusions}

Although the current study provides additional psychometric refinement of the ATSSPCQ, which may be appealing to some SPCs, additional efforts should be made to further establish construct validity of the new instrument, including crossvalidating the present findings with other independent samples to confirm the model. If a model is distinctive to a group, then the approach may be of limited utility (Marsh, 1994). It is critical for future researchers to explore whether the factor structure of the SPA-R is similar for various populations (e.g., ethnic or sport groups) and to determine the predictive utility within various populations (i.e., the meaning and consequences of the attitudes for those different groups). For example, research has indicated that perceptions may change according to (a) the reason the SPC is sought (e.g., emotional concerns or sport performance issues), (b) the SPC's training (e.g., exercise science or counseling psychology), (c) the SPC's past sport experience, or (d) where the SPC's office is located (Linder et al., 1989; Martin et al., 1997, 2001; Van Raalte et al., 1990). On the contrary, Linder et al. (1991) and Hankes (1996) did not find that SPC's academic training or past athletic experience influenced perceptions about consultants. Future research may want to assess these factors using the SPA-R instrument to determine if they influence attitudes toward seeking sport psychology consultation. Of course, more than a little of the contemporary CFA literature is bogged down in details of using computer packages or caught up in evaluating the numerous GOF indexes rather than discussing substantive findings and possible implications related to the topic of interest (see Goodwin, 1999; Nunnally \& Berstein, 1994).

Limited knowledge is available about the sport psychology attitudes and expectations of athletes, coaches, and significant others (e.g., parents) from different countries (Van Raalte et al., 1996). Clearly, more information is needed regarding how demographic characteristics such as gender, ethnicity, age, type of sport (e.g., physical contact versus nonphysical contact), type of competition (e.g., Paralympics), athletic maturity, and previous experience seeking psychological assistance influences expectations of and attitudes toward sport psychology consultation. Developing a better understanding of these issues could help sport psychology practitioners improve the manner in which they present and provide services.

\section{References}

Andersen, M. (1993). Questionable sensitivity: A comment on Lee and Rotella. The Sport Psychologist, 7, 1-3. 
Anshel, M.H. (1990). Perceptions of Black intercollegiate football players: Implications for sport psychology consultants. The Sport Psychologist, 4, 235-248.

Atkinson, D.R., \& Lowe, S.M. (1995). The role of ethnicity, cultural knowledge, and conventional techniques in counseling and psychotherapy. In J.G. Ponterotto, J.M. Casas, L.A. Suzuki, \& C.M. Alexander (Eds.), Handbook of multicultural counseling (pp. 387-414). Thousand Oaks, CA: Sage.

Brooks, J.E., \& Bull, S.J. (1999). Perceptions of the sport psychologist by female university athletes. Journal of Sports Sciences, 17, 205-212.

Browne, M.W., \& Cudeck, R. (1993). Alternative ways of assessing model fit. In K.A. Bollen \& J.S. Long (Eds.), Testing structural equation models (pp. 136-162). Newbury Park, CA: Sage.

Bull, S.J. (1995). Mental training adherence in elite junior tennis players. In R. VanfraechemRamway \& Y. Vanden Auweele (Eds.), Proceedings of the IXth European Congress on Sport Psychology, Belgium, 1144-1151.

Coakley, J., \& White, A. (1992). Making decisions: Gender and sport participation among British adolescents. Sociology of Sport Journal, 9, 20-35.

Cronbach , L.J. (1951). Coefficient alpha and the internal structure of tests. Psychometrika, 16, 297-334.

du Toit, S.H.C., du Toit, M., Jöreskog, K.G., \& Sörbom, D. (1999). Interactive LISREL. Chicago: Scientific Software International.

Esters, I.G., Cooker, P.G., \& Ittenbach, R.F. (1998). Effects of a unit of instruction in mental health on rural adolescents' conceptions of mental illness and attitudes about seeking help. Adolescence, 33, 469-476.

Fischer, E.H., \& Farina, A. (1995). Attitudes toward seeking professional psychological help: A shortened form and considerations for research. Journal of College Student Development, 36, 368-373.

Fischer, E.H., \& Turner, J.L. (1970). Orientations to seeking professional help: Development and research utility of an attitude scale. Journal of Consulting and Clinical Psychology, 35, 79-90.

Floyd, F.J., \& Widaman, K.F. (1995). Factor analysis in the development and refinement of clinical assessment instruments. Psychological Assessment, 7, 286-299.

Foster, G., Shelton, R., \& Lester, D. (Producers), \& Shelton, R. (Director). (1996). Tin cup [Film]. (Available from Warner Brothers, Inc., in Association with New Regency Enterprises, Alameda Avenue, 5th floor, Burbank, CA 91522-1705)

Garland, A.F., \& Zigler, E.F. (1994). Psychological correlates of help-seeking attitudes among children and adolescents. American Journal of Orthopsychiatrics, 64, 586-593.

Goldberg, A.D., \& Chandler, T. (1995). Sports counseling: Enhancing the development of the high school student-athlete. Journal of Counseling and Development, 74, 39-44.

Goodwin, L.D. (1999). The role of factor analysis in the estimation of construct validity. Measurement in Physical Education and Exercise Science, 3, 85-100.

Greaser, J.R. (1992). Motivational determinants of a sport specific behavior: The effects of attitudes and expectations upon the intentions of sport competitors to practice sport psychological skills. Unpublished doctoral dissertation, University of Connecticut, Storrs.

Hankes, D.M. (1996). Applied sport psychology consultation: Effects of academic training, past athletic experience, and interpersonal skill on female athletes' ratings. Unpublished doctoral dissertation, University of North Texas, Denton.

Harmison, R.J., \& Petrie, T.A. (1998). Factor analysis of the Attitudes toward Seeking Sport Psychology Consultation Questionnaire (ATSSPCQ): A replication and extension [Abstract]. Journal of Applied Sport Psychology, 10, S80. 
Hu, L., \& Bentler, P.M. (1999). Cutoff criteria for fit indexes in covariance structure analysis: Conventional criteria versus new alternatives. Structural Equation Modeling, 6, 1-55.

Jackson, R. (Executive Producer). (1998, October 11). Total game: "Invest in Yourself" Goin' deep. New York, NY: Twentieth Century Fox Film Corporation.

Jöreskog, K.G., \& Sörbom, D. (1993). LISREL 8: Structural equation modeling with the SIMPLIS command language. Chicago: Scientific Software International.

Kelloway, E.K. (1998). Using LISREL for structural equation modeling: A researcher's guide. Thousand Oaks, CA: Sage.

Kenney, G.E. (1994). Multicultural investigation of counseling expectations and preferences. Journal of College Student Psychotherapy, 9, 21-39.

Lee, C.L., \& Rotella, R.J. (1991). Special concerns and considerations for sport psychology consulting with Black student athletes. The Sport Psychologist, 5, 365-369.

Linder, D.E., Brewer, B.W., Van Raalte, J.L., \& DeLange, N. (1991). A negative halo for athletes who consult sport psychologists: Replication and extension. Journal of Sport and Exercise Psychology, 13, 133-148.

Linder, D.E., Pillow, D.R., \& Reno, R.R. (1989). Shrinking jocks: Derogation of athletes who consult a sport psychologist. Journal of Sport and Exercise Psychology, 11, 270-280.

Lloyd, C. (Producer), \& Lee, D. (Director). (1997). Frasier: Head games (Episode 77). Los Angeles, CA: Grub Street Productions in association with Paramount Network Television.

Malina, R.M. (1996). The young athlete: Biological growth and maturation in a biocultural context. In F.L. Smoll \& R.E. Smith (Eds.), Children and youth in sport: A biopsychosocial perspective (pp. 161-186). Dubuque, IA: Brown \& Benchmark.

Marsh, H.W. (1994). Confirmatory factor analysis models of factor invariance: A multifaceted approach. Structural Equation Modeling, 1, 5-34.

Martin, S.B. (1998). High school athletes' attitudes toward seeking sport psychology services. Journal of Applied Sport Psychology, 10, S156.

Martin, S.B., Akers, A., Jackson, A.W., Wrisberg, C.A., Nelson, L., Leslie, P.J., \& Leidig, L. (2001). Male and female athletes' and nonathletes' expectations about sport psychology consulting. Journal of Applied Sport Psychology, 13(1), 19-40.

Martin, S.B., Wrisberg, C.A., Beitel, P.A., \& Lounsbury, J. (1997). NCAA Division I athletes' psychological skills and attitudes toward seeking sport psychology consultation: The development of an objective instrument. The Sport Psychologist, 11, 201218.

Mislevy, R.J. (1986). Recent developments in the factor analysis of categorical variables. Journal of Educational Statistics, 11, 3-31.

Messner, M.A. (1992). Power at play: Sports and the problem of masculinity. Boston: Beacon Press.

Nunnally, J.C., \& Berstein, I.H. (1994). Psychometric theory. (3rd ed.). New York: McGrawHill.

Pedhazur, E. J., \& Schmelkin, L.P. (1991). Measurement, design, and analysis: An integrated approach. Hillside, NJ: Lawrence Erlbaum.

Ravizza, K. (1988). Gaining entry with athletic personnel for season-long consulting. The Sport Psychologist, 2, 243-254.

Schumacker, R.E., \& Beyerlein, S.T. (2000). Confirmatory factor analysis with different correlation types and estimation methods. Structural Equation Modeling, 7, 629636.

Schumacker, R.E., \& Lomax, R.C. (1996). Beginner's guide to structural equation modeling. Mahwah, NJ: Erlbaum. 
Steenkamp, J.E.M., \& Baumgartner, H. (1998). Assessing measurement invariance in crossnational consumer research. Journal of Consumer Research, 25, 78-90.

Steiger, J.H. (1990). Structural model evaluation and modification: An interval estimation approach. Multivariate Behavioral Research, 25, 173-180.

Tinsley, H.E.A., \& Tinsley, D.J. (1987). Uses of factor analysis in counseling psychology research. Journal of Counseling Psychology, 34, 414-424.

Tinsley, H.E.A., Workman, K.R., \& Kass, R.A. (1980). Factor analysis of the domain of client expectations about counseling. Journal of Counseling Psychology, 27, 561570.

Tolson, J. (2000, July 3). Into the zone. The kind of mental conditioning that makes athletes into superstars also helps ordinary folks become extraordinary. U.S. News \& World Report [On-line]. Available: http://www.usnews.com/news/issue/000703/zone.htm

Van Raalte, J.L., Brewer, B.W., Brewer, D.D., \& Linder, D.E. (1992). NCAA Division II college football players' perceptions of an athlete who consults a sport psychologist. Journal of Sport \& Exercise Psychology, 14, 273-282.

Van Raalte, J.L., Brewer, B.W., Linder, D.E., \& DeLange, N. (1990). Perception of sportoriented professionals: A multi-dimensional scaling analysis. The Sport Psychologist, 4, 228-234.

Van Raalte, J.L., Brewer, D.D., Matheson, H., \& Brewer, B.W. (1996). British athletes' perceptions of sport and mental health practitioners. Journal of Applied Sport Psychology, 8, 102-108.

Wrisberg, C.A., \& Martin, S.B. (1994). Attitudes of African-American and Caucasian athletes towards sport psychology consultants. Paper presented at the annual meeting of the Association for the Advancement of Applied Sport Psychology, Incline Village, NV.

Yambor, J., \& Connelly, D. (1991). Issues confronting female sport psychology consultants working with male student-athletes. The Sport Psychologist, 5, 304-312.

\section{Acknowledgments}

The authors thank the athletes and coaches who participated in the study. Appreciation is also extended to T.J. Filipowicz, Theanna Kellogg, and Cindy Peavey for their assistance with the data entry and Gerhard Mels and Allen Akers for their assistance with the analyses. Finally, a special thanks go to Vikki Krane and the anonymous reviewers for their valuable feedback on a previous version of the manuscript.

Manuscript submitted: December 19, 2000

Revision received: June 25, 2001 